\title{
EUROSON 2020 - The program is in the making!
}

Dear Ultrasound friends,

We are now preparing for the $32^{\text {nd }}$ EUROSON conference that will take place in Bergen, Norway from 11-13 of June 2020 . Please mark your calendar. We hope that many of you will take the opportunity to join the conference and to visit Bergen or its surroundings. We are now in the process of putting together teaching sessions, including lectures, free-paper presentations, hands-on training possibilities and a postgraduate course in liver elastography that we hope appeal to ultrasound users beginners or experienced. We thank the National Societies of EFSUMB for valuable input on who they propose as speakers from their country. We believe that this is a resource we will use in order to finalize an attractive and balanced program emphasizing both clinical skills as well as science and new developments.

Our venue is the Edvard Grieg Concert hall with opportunities for several parallel sessions and a great space for exhibitions, poster area and mingling. The venue is situated in the centre of Bergen with walking distance to most attractions in the centre of Bergen.

\section{EUROSON + NFUD + Sonoscandinavia}

Next year we combine all good forces in order to make the most of coming together to learn ultrasound or present your research. The conference will be a joint conference of EUROSON and Sonoscandinavia, which will be taking place for the $4^{\text {th }}$ time, and is directed toward general practitioners and acute medicine practitioners. The program will be separate, but all EUROSON participants may follow the lectures of Sonoscandinavia. For the practical hands on sessions, one has to register separately for Sonoscandinacvia. However, there will be other hands-on opportunities in the ordinary program. The Norwegian Society for Diagnostic Ultrasonography (NFUD) is also part of the organizing committee and Scientific Committee. EUROSON 2020 is also the annual meeting of NFUD. The Norwegian society has a tradition of having a strong attendance from obstetricians and ultrasound performing mid-wives. In 2020 there will be a parallel session for US in obstetrics throughout the program.

\section{Post-graduate course in Liver elastography}

Elastography of liver has established itself as an important follow-up parameter in chronic liver disease and may substitute liver biopsy for the evaluation of liver fibrosis. We have been able to gather a strong lineup of Europe's most experienced practitioners of liver elastography to teach theory and practice at our Liver elastography postgraduate course on Thursday, June 12, 2020. Here we will gather several brands of elastography, you may increase your knowledge and spectrum of this valuable method in hepatology. Due to the hands-on training, we have a limited space of 60 participants in this course.

\section{Climb a mountain!}

If you need air or space after concentrating on new knowledge in US, we recommend visiting one of our mountains. They are all accessible on foot, but some are easier to get to by cable car (Ulriken) or by a funicular (Fløyen). From these mountains, you will have a beautiful view of Bergen and the islands outside to the west. This year, a flight of broad stone steps was completed, to the very top of mount Ulriken, 643 meters above sea level. 


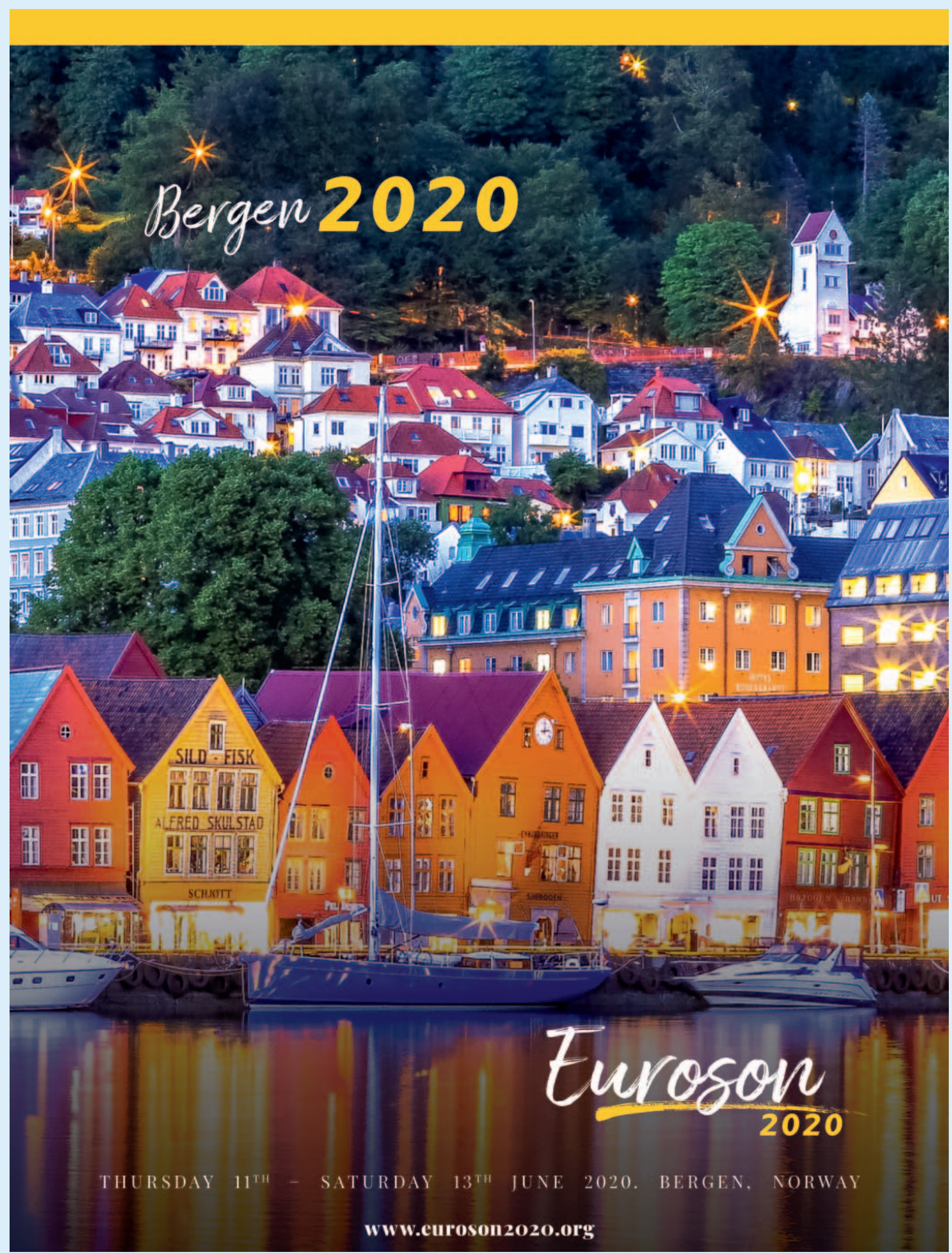

